\title{
DIREITOS DA PERSONALIDADE E LIBERDADE DE EXPRESSÃO - 0 JULGAMENTO NO STF SOBRE A CONSTITUCIONALIDADE DAS BIOGRAFIAS NÃO AUTORIZADAS (ADI 4815/DF)
}

\author{
Ricardo dos Santos Castilho* \\ Shary Kalinka Ramalho Sanches**
}

SUMÁRIO: Introdução; 1.1 O Homem como Sujeito de Direitos e sua Proteção pelos Direitos Humanos; 2 ALiberdade de Expressão como Direito Humano Fundamental; 3 Direitos da Personalidade como Direitos Humanos Fundamentais; 4 Direitos da Personalidade e Liberdade de Expressão: O Julgamento no STF sobre a Constitucionalidade das Biografias não Autorizadas (ADI 4815); 5 Considerações Finais; Referências.

RESUMO: A Ação Direita de Inconstitucionalidade 4.815 questionou a constitucionalidade dos artigos 20 e 21 do Código Civil no que se refere à prévia necessidade de autorização para publicação de obras biográficas pela pessoa biografada, de coadjuvantes ou de sucessores (em caso de óbito daqueles). Isso porque a Constituição brasileira no inciso IX do artigo $5^{\circ}$ determina a liberdade de expressão e a proibição da censura. Porém os direitos privados, acima citados, também são tutelados em sede constitucional, gerando a colisão entre direitos fundamentais. Esta pesquisa, do tipo histórico-descritiva, apresenta dois objetivos: investigar os direitos humanos envolvidos, quais sejam, a liberdade de expressão e os direitos da personalidade (considerados em sentido estrito) e analisar a decisão do julgamento em comento. Ao final, a ação foi julgada procedente para dar interpretação conforme a Constituição sem redução de texto aos artigos 20 e 21 da Lei Civil, declarando inexigível a autorização, em conformidade com os direitos fundamentais à liberdade de pensamento, de expressão, de produção científica e de criação artística, reafirmando, contudo, a inviolabilidade da intimidade, da privacidade, da imagem e da honra.

PALAVRAS-CHAVE: Direitos Humanos; Liberdade de Expressão; Direitos da Personalidade; Biografias Não Autorizadas.

\footnotetext{
Pós-doutor em Direito pela Universidade Federal de Santa Catarina (UFSC); Pesquisador e Docente de Direitos Humanos dos Programas de Pós-Graduação Stricto sensu Mestrado e Doutorado da FADISP e UNIFIEO, Brasil.

${ }^{* *}$ Doutoranda no Programa de Pós-Graduação Stricto sensu da Faculdade Autônoma de Direito (FADISP) em Função Social do Direito Constitucional; Docente da disciplina Direito Constitucional, da Universidade Federal do Mato Grosso do Sul (UFMS), Brasil; E-mail: skramalho@yahoo.com.br
} 


\title{
PERSONAL RIGHTS AND FREEDOM OF SPEECH - SENTENCE OF THE SUPREME FEDERAL COURT ON THE CONSTITUTIONALIT Y OF NON-AUTHORIZED BIOGRAPHIES (ADI 4815/DF)
}

\begin{abstract}
The suit on non-constitutionality 4815 questioned the constitutionality of Article 20 and 21 of the Brazilian Civil Law with regard to the previous authorization for the publishing of biographies by the person himself, by helpers or inheritors. The Brazilian Constitution, $\S 9$ Art. 15, determines freedom of speech and the prohibition of censorship. Personal rights, however, are also protected by the Constitution, wherein lies a conflict in fundamental rights. Current historical and descriptive research aims at investigating human rights involved, such as freedom of speech and personal rights (in a strict sense) and at analyzing the decision of the sentence. The suit was judged favorable to give the interpretation of the Constitution without diminishing the articles 20 and 21 of the Brazilian Civil Law, declaring authorization unenforceable complying with the fundamental rights of freedom of thought, speech, scientific production and artistic creativity. It reaffirms the inviolability of private life, privacy, image and honor.
\end{abstract}

KEY WORDS: Human Rights; Freedom of Speech; Personal Rights; Non-Authorized Biographies.

\section{DERECHOS DE LA PERSONALIDAD Y LIBERTAD DE EXPRESIÓN - EL JUZGAMIENTO EN EL STF SOBRE LA CONSTITUCIONALIDAD DE LAS BIOGRAFÍAS NO AUTORIZADAS}

RESUMEN: La acción Derecha de Inconstitucionalidad 4815 ha cuestionado la constitucionalidad de los artículos 20 y 21 del Código Civil en lo que se refiere a la previa necesidad de autorización para publicación de obras biográficas por la persona biografiada, coadyuvantes o de sucesores (en caso de óbito de aquellos). Eso ocurre porque la Constitución brasileña en el inciso IX del artículo $5^{\circ}$ determina la libertad de expresión y la prohibición de la censura. Sin embargo, los derechos privados citados también son tutelados en la base constitucional, llevando a la colisión entre derechos fundamentales. Esta investigación histórica-descriptiva presenta dos objetivos: investigar los derechos humanos entramados, cuáles sean, la libertad de expresión y los derechos de la personalidad (considerados en sentido estricto) y analizar la decisión del juzgamiento comentado. Al final, la acción fue juzgada procedente para dar la interpretación conforme la Constitución sin reducción de texto a los artículos 20 y 21 de la Ley Civil, declarando inexigible la autorización, en conformidad con los derechos fundamentales a la libertad del pensamiento, de expresión, de producción científica y de creación artística, reafirmando, no obstante, la inviolabilidad de la intimidad, de la privacidad de la imagen y de la honra. 
PALABRAS-CLAVE: Derechos Humanos; Libertad de Expresión; Derechos de la Personalidad; Biografías no autorizadas.

\section{INTRODUÇÃO}

Embora a democracia constitucional tenha se instalado no Ocidente com intensa força após as revoluções liberais, na América Latina do século XX, os Estados autoritários e opressores se fortaleceram e tomaram o poder na quase totalidade dos países, inclusive no Brasil. O exercício arbitrário e a manutenção da autoridade déspota invariavelmente significam a cassação de inúmeros direitos humanos da população. Nesse contexto, a história revela que a liberdade de expressão é um dos primeiros, senão o primeiro direito, a sofrer maciça restrição.

A censura normalmente é relacionada a ato exclusivo do Estado arbitrário. Contudo ela também está presente nas relações entre particulares e nos vínculos sociais em geral em que haja interesses para que informações não sejam reveladas.

Em esfera pública ou privada, a expressão tem recebido ataques de toda ordem. Na Europa medieval, foram impostas proibições por séculos. Mas, desde que as estacas do liberalismo moderno foram firmadas, à liberdade de expressão restou o grande fundamento ético e político das futuras revoluções burguesas, podendo-se afirmá-la como um termômetro indicador da saúde democrática de um país.

Outra grande contribuição liberal foi o reconhecimento do supremo valor da dignidade do homem, reveladora em sua proteção integral. Sobre o conceito de pessoa humana debruçaram-se Locke, Hobbes e Kant e foi a partir do amadurecimento das suas inaugurais contribuições teóricas que pela primeira vez se declarou a dignidade como um atributo humano (em 1948, na Declaração de Direitos Humanos).

Os direitos da personalidade, direitos humanos de berço, a partir de meados do século XX começaram a ser estendidos às relações privadas. Não compunham originalmente o rol dos direitos privados até então, estando ausentes dos ordenamentos civis como, por exemplo, do Código alemão, do francês e do brasileiro de 1916.

A Ação Direta de Inconstitucionalidade 4.815 refere-se, numa análise mais breve, ao confronto entre o direito constitucional à livre expressão (incisos IV e IX do art. $5^{\circ} \mathrm{da}$ Constituição brasileira) e ao direito privado à intimidade e à privacidade. 
A ação teve por objeto o pedido de inconstitucionalidade parcial sem redução de texto dos artigos 20 e 21 do Código Civil para que, mediante interpretação conforme a Constituição, fosse afastada a necessidade do consentimento da pessoa biografada e das pessoas retratadas como coadjuvantes para a publicação ou veiculação de obras biográficas, literárias ou audiovisuais.

Porém, por outra perspectiva, sendo os direitos da personalidade propriamente direitos constitucionais, a solução (do conflito) não estaria na tradicional resolução de antinomia das leis (hierarquia) vez que as normas são de mesma envergadura constitucional, verificando-se, então, a colisão entre direitos fundamentais. Assim, propugnou-se pela técnica da ponderação.

O Supremo Tribunal Federal já havia decido, por ocasião da ADPF 130/DF, que o regime constitucional da liberdade de informação jornalística proíbe qualquer tipo de censura à liberdade de imprensa ou, como sobretutela, das liberdades de manifestação do pensamento, de informação e de expressão artística, científica, intelectual e comunicacional. Na chancela do tribunal, o regime democrático não é receptivo à censura.

A presente pesquisa tem dois objetivos: investigar os direitos humanos envolvidos no julgamento, quais sejam, a liberdade de expressão e os direitos da personalidade (considerados em sentido estrito) e analisar a decisão do julgamento em comento.

\subsection{O HOMEM COMO SUJETO DE DIREITOS E SUA PROTEÇÃO PELOS DIREITOS HUMANOS}

Sujeito de direitos é um conceito filosófico-jurídico estável nos dias atuais. Seu surgimento é fruto de complexa construção liberal-burguesa de homem (indivíduo) e de Estado, que pretendeu romper com a dominação monárquico/ eclesiástica.

Locke contribuiu criando uma concepção individualista do homem. Para ele, consoante a Hobbes ${ }^{1}$, o indivíduo precedeu a sociedade vivendo em plena liberdade e igualdade, no denominado estado de natureza ${ }^{2}$.

É no pós-medievo que desponta a noção de sujeito. Com a filosofia moderna ocidental, o homem galga ocupar posição de centralidade, dotado de racionalidade

${ }^{1}$ HOBBES, Thomas. Leviatã. São Paulo: Martin Claret, 2002.

2 LOCKE, John. Segundo Tratado sobre o governo civil. Tradução Magda Lopes; Marisa Lobo da Costa. Petrópolis: Vozes, 1987. 
e consciência, e parte em busca do conhecimento sobre si mesmo e sobre o mundo. Surge a subjetividade num cenário de profundas transformações sociais, ideológicas e políticas.

O autor central dessa grande revolução sobre o ser humano é Descartes, para quem o pensamento é que possibilita a existência do sujeito. Primeiro representante do movimento racionalista clássico rompeu com a escolástica medieval e propôs o caminho por meio da dúvida metódica para encontrar a certeza do sujeito pensante. Por isso o "Penso, logo existo"3 reposiciona o homem na história - o eu cartesiano merece uma atenção especial.

Isso se dá em razão do surgimento da figura do indivíduo, concepção moderna de sujeito. É esse homem que toma consciência de si mesmo, de sua existência singular, de sua vida racional e psicológica, não sendo apenas uma parte de um todo anônimo. Ele existe em si mesmo e se torna titular de suas crenças, ideias e decisões.

Até esse período, a filosofia investigava o mundo para conhecê-lo. A partir disso, especialmente mediante as contribuições de Kant, inaugurou-se uma nova perspectiva que relaciona o sujeito com o próprio conhecimento produzido. Para o autor, todo conhecimento só é possível porque o sujeito cognoscente o possibilita em decorrência de suas formas a priori, ou seja, o conhecimento só é possível no e por meio do sujeito.

Em Crítica à Razão Pura ${ }^{4}$, a perspectiva kantiana propõe principalmente duas origens para o conhecimento: o entendimento, que já detém os conceitos com os quais pensa os objetos; e os sentidos, por meio dos quais os objetos são apreendidos.

Mas, como a racionalidade não seria importante apenas na seara teórica, foi em Crítica à Razão Prática a conclusão de que a razão humana é a fonte de regras práticas que devem reger a vontade humana, válidas para todos os seres racionais, independentemente da experiência de cada um - o que garante a autossuficiência ao ser. Na esteira desse pensamento, a moralidade é alicerçada pela razão pura que é objetiva e prática em si. O homem é autônomo porque pensa, não sendo dirigido por suas paixões inferiores, mas, sim, por sua razão.

3 DESCARTES, René. Discurso do método. Tradução Maria Ermantina Galvão. São Paulo: Martins Fontes, 2001.

${ }^{4}$ KANT Immanuel. Crítica à razão pura. 5. ed. Tradução Manuela Pinto dos Santos; Alexandre Fradique Morujão. Lisboa: Fundação Calouste Gulbenkian, 2001.

5 KANT, Immanuel. Crítica à razão prática. Tradução Afonso Bertagnoli. São Paulo: Brasil, 2004. Disponível em: $<$ http://www.ebooksbrasil.org/eLibris/razaopratica.html > . Acesso em: 29 set. 2015. 
Gradativamente, o sujeito, que agora consegue enxergar a si mesmo em sua própria essência pensante, começa a se (auto) descobrir em relação ao outro. E esse outro se mostra diferente. A multiplicidade se revela e a construção das relações principia a ser moldada no contato com a pluralidade dos/com os outros. E é justamente nessa tensa relação de alteridade que nascem os sujeitos de direitos. Consciente de sua pessoalidade e de sua singularidade, tanto física quanto emocional, o sujeito começou a avocar para si prerrogativas, a exigir que sua existência corpóreaindividual tivesse sentido e fosse respeitada pelos pares e pelo coletivo.

Emerge a concepção de individualidade (diferente de individualismo, este mais afeto ao egoísmo) na qual o homem, paulatinamente, ascende à categoria de pessoa humana. Vale ressaltar, com base no que postula Canotilho, que esse processo contou o auxílio do constitucionalismo, que se apresentou como o movimento de limitação do poder estatal com fins garantísticos ${ }^{6}$, viabilizando o nascimento e o reconhecimento dos direitos humanos, principal suporte de estabilidade ao conceito ético-jurídico de pessoa humana.

Se o constitucionalismo adquiriu seus contornos mais definidos no período moderno, há quem identifique resquícios embrionários desse movimento em tempos mais remotos, como Karl Loewenstein, para quem seu surgimento se deu na Antiguidade clássica ${ }^{7}$, no judaico-cristianismo.

Segundo o autor, nesse período todas as pessoas da comunidade deviam igualmente obediência à mesma lei, encontrando-se posicionadas horizontalmente diante dela. Reis, sacerdotes e demais judeus tinham a mesma "estatura" perante a autoridade superior não humana (o grande Yabweb). Com o advento do cristianismo, o indivíduo ganhou destaque e a igualdade entre as pessoas foi difundida - todos são igualmente pecadores e todos são, da mesma forma, importantes ${ }^{8}$.

É da Inglaterra de 1215 o primeiro documento de natureza constitucional, cujo principal mérito foi cunhar a limitação do poder estatal. Já no século XVII, ainda em solo inglês, inúmeros documentos estabeleceram embriões de garantias e liberdades, tais como: a Petição de Direito, de 1628; o Act of Habeas Corpus, de 1679, e o Bill of Rigths - carta elaborada e promulgada em 1689 pelo Parlamento resguardando o direito à propriedade e à liberdade de expressão.

Por outro lado, embora todos esses documentos europeus tivessem sido apresentados com o único (e valoroso) objetivo de limitar o poder, foi na América

${ }_{6}^{6}$ CANOTILHO, J. J. Gomes. Direito constitucional e teoria da constituição. 6. ed. Coimbra: Almedina, 1993.

7 LOEWENSTEIN, Karl. Teoría de la Constitución. 2. ed. Barcelona: Ariel, 1970.

8 COMPARATO, Fábio Konder. A afirmação histórica dos direitos humanos. 6. ed. São Paulo: 2008. 
do Norte que esse paradigma foi alterado. Isso remete à configuração da Declaração de Direitos da Virgínia, de 1776. Muito significativa porque pela primeira vez se reconhece que alguns direitos são certos e naturais a todos os homens.

Etienne-Richard Mbaya ${ }^{9}$ descreve com precisão a construção dos direitos humanos:

Desde então, os direitos humanos situam-se num combate de idéias, constituindo o florão de uma vigilância do espírito face às pressões dos poderes estabelecidos, dos hábitos mentais, dos modos de governo herdeiros de ordens mais antigas. Como o espírito, a idéia é dinâmica; ela atravessa o tecido da história para inventar algo novo; ela perturba. Não se trata de um simples reflexo de certo estado de coisas. Igualmente, a Declaração dos direitos do homem é esse movimento do espírito ao mesmo tempo em que responde à necessidade elementar de proteção, no plano físico e moral, contra os abusos de poder e as desigualdades das relações de força.

$[\ldots]$

A percepção dos direitos humanos está condicionada, no espaço e no tempo, por múltiplos fatores de ordem histórica, política, econômica, social e cultural. Portanto, seu conteúdo real será definido de modo diverso e suas modalidades de realização variarão.

No plano internacional mais recente são muitas as conquistas, como a Primeira Convenção de Genebra (1864) sobre os direitos humanitários das vítimas de conflitos armados e o Tratado de Versalhes (1919) sobre os direitos dos trabalhadores. Porém os mais expressivos textos são os legislados após a Segunda Grande Guerra.

O ápice dessa rede normativa foi a Declaração Universal dos Direitos do Homem, aprovada pela Assembleia Geral das Nações Unidas (1948) que no artigo $1^{\circ}$ determinou: "Todos os homens nascem livres e iguais em dignidade e direitos. São dotados de razão e consciência e devem agir em relação uns aos outros com espírito de fraternidade" ${ }^{10}$.

E, nos dias atuais, após séculos de avanços, retrocessos e implementações na normatização, o que se poderia afirmar como direitos humanos? Nas palavras de Louis Henkin ${ }^{11}$ :

\footnotetext{
9 MBAYA, Etienne-Richard. Gênese, evolução e universalidade dos direitos humanos frente à diversidade de culturas. p.20-21. Disponível em: < http://www.revistas.usp.br/eav/article/viewFile/8993/10545 > Acesso em: 20 out. 2015.

${ }^{10}$ ORGANIZAÇÃO DAS NAÇÕES UNIDAS. Declaração Universal dos Direitos do Homem. (1948). Disponível em: $<$ http://www.direitoshumanos.usp.br/index.php/Declara\%C3\%A7\%C3\%A3o-Universal-dos-Direitos-Huma nos/declaracao-universal-dos-direitos-humanos.html > . Acesso em: 20 jul. 2015.

${ }^{11}$ HENKIN, Louis. The rights of man today. New York: Columbia University Press, 1988. p. 1-3.
} 
Direitos humanos são um termo de uso comum, mas não decididamente definido. Esses direitos são concebidos de forma a incluir aquelas 'reivindicações morais e políticas que, no consenso contemporâneo, todo ser humano tem ou deve ter perante sua comunidade ou governo', reivindicações estas reconhecidas como de direito e não apenas por amor ou benevolência.

Já para Alexandre de Moraes seria: "um conjunto institucionalizado (positivado) de direitos e garantias do ser humano que tem por finalidade o respeito à sua dignidade por meio de sua proteção contra o arbítrio do poder estatal e o estabelecimento de condições mínimas de vida e o desenvolvimento da personalidade humana". ${ }^{12}$

A dignidade da pessoa humana é o valor superior que afasta o tratamento coisificado ao homem, como explica Flávia Piovesan ${ }^{13}$ :

Intenta-se a reaproximação da ética e do direito, e, neste esforço, surge a força normativa dos princípios, especialmente do princípio da dignidade humana. Há um reencontro com o pensamento kantiano, com as ideias de moralidade, dignidade, direito cosmopolita e paz perpétua. Para Kant, as pessoas devem existir como um fim em si mesmo e jamais como um meio, a ser arbitrariamente usado para este ou aquele propósito. Os objetos têm, por sua vez, um valor condicional, enquanto irracionais, por isso são chamados "coisas", substituíveis que são por outras equivalentes. Os seres racionais, ao revés, são chamados "pessoas", porque constituem um fim em si mesmo, têm um valor intrínseco absoluto, são insubstituíveis e únicos, não devendo ser tomados meramente como meios. As pessoas são dotadas de dignidade, na medida em que têm um valor intrínseco. Desse modo, ressalta Kant, deve-se tratar a humanidade, na pessoa de cada ser, sempre como um fim em si mesmo, nunca como um meio.

Pode-se afirmar que os direitos humanos são, em última análise, os meios que possibilitaram e possibilitam a luta e a conquista pela dignidade da pessoa humana ${ }^{14}$.

\footnotetext{
${ }^{12}$ MORAES, Alexandre de. Direitos humanos fundamentais: teoria geral. Comentários dos artigos $1^{\mathrm{o}}$ ao $5^{\circ}$ da Constituição. 2. ed. São Paulo: Atlas, 1997, p. 28.

${ }^{13}$ PIOVESAN, Flávia. Direitos Humanos e o direito constitucional internacional. 14. ed. São Paulo: Saraiva, 2013, p.88.

${ }^{14}$ CARVALHO, Salo de; FLORES, Joaquím Herrera; RUBIO, David Sánchez. Direitos Humanos e globalização: fundamentos e possibilidades desde a teoria crítica. Brasília: Lumem Juris, 2004.
} 


\section{A LIBERDADE DE EXPRESSÃO COMO DIREITO HUMANO FUNDAMENTAL}

A livre expressão foi fortalecida no fim do renascimento por alguns fatores. A Reforma Protestante, por exemplo, desempenhou papel decisivo uma vez que reclamou inúmeras liberdades, seguiu energicamente contra a censura papal e alcançou o resultado inicial esperado: a liberdade para interpretar as Sagradas Escrituras; avanço esse que possibilitou o direito de livre culto.

O cenário de confronto instalado (não só no campo das ideias como no armado) favoreceu o fortalecimento de outras demandas revolucionárias já existentes. Essa crescente busca pela liberdade de crença e consciência inundou a Europa e varreu o velho continente, derrubando monarquias e inaugurando novos paradigmas nas esferas política, social, cultural e filosófica. ${ }^{15}$

É desse período a obra "Carta sobre a Tolerância" (1689), de Locke, que trata de assuntos que remetem ao campo religioso e do respeito pelas escolhas individuais, desde que elas não prejudiquem os outros. Assenta-se a obra no fundamento jusnaturalista da liberdade e igualdade, trazendo no bojo de sua reflexão: que a crença deve ser espontânea sob pena de não ser genuína; que jamais pode ser forçada por homem ou instituição alguma, consistindo tal atitude contrária ao que determina a palavra de Deus; que a conversão há de ser livre e a forma de prestar culto também, pois, se Deus não deixou prescritos todos os detalhes litúrgicos, é porque aceita várias formas de adoração ${ }^{16}$. O seu pensamento constitui um marco divisório para o livre pensar e o livre expressar.

Em meados do século XIX, o democrata liberal, Stuart Mill, assiste à retomada do conservadorismo elaborando a obra 'Sobre a liberdade' que se tornou referência (após Locke) para a liberdade de expressão. Nela, o autor reafirma todas as liberdades humanas mas então sob a perspectiva do utilitarismo (conquista da maior quantidade de felicidade estendida ao maior número de pessoas). Todos deveriam ter liberdade em optar pelo pensar e pelo agir. Não pregava a irresponsabilidade, pelo contrário, assentava a cada um a responsabilidade pelos próprios atos. Creditava ao Estado a função de prover um ambiente seguro para que as pessoas pudessem progredir por si mesmas e retirava deste mesmo Estado qualquer possibilidade de calar o cidadão.

\footnotetext{
${ }^{15}$ OLIVEIRA JÚNIOR, Claudomiro Batista de. Afirmação histórica e jurídica da liberdade de expressão. In: CONGRESSO NACIONAL DO CONPEDI, 17., 2008, Brasília. Anais... Florianópolis: CONPEDI, 2008. p. 5777-5795. Disponível em: < http://www.conpedi.org.br/manaus/arquivos/anais/brasilia/05_395.pdf > . Acesso em: 15 set. 2015

${ }^{16}$ LOCKE, John. Carta sobre a tolerância. Tradução Ari Ricardo Tank Brito. São Paulo: Hedra, 2007.
} 
Defendia que a ideia de alguém nunca era somente sua e, ao privá-la de ser conhecida, estaria produzindo um dano, pois, se fosse verdadeira, o outro perdeu possível contribuição; se falsa ou equivocada, também perdeu o emissor de ser confrontado para caminhar rumo à verdade. Considerava inseparáveis as liberdades de pensamento e de discussão:

A liberdade de imprimir e de publicar opiniões pode parecer que cai sob um princípio diferente, uma vez que pertence àquela parte da conduta social que concerne às outras pessoas. Mas, sendo quase de tanta importância como a própria liberdade de pensamento, e repousando, em grande parte sobre as mesmas razões, é praticamente inseparável dela ${ }^{17}$.

A liberdade de expressão firmou suas bases também nos nascentes Estados Unidos da América. A primeira emenda à Constituição trata especificamente desse direito e o faz como símbolo máximo do respeito, da autonomia e do desenvolvimento de um povo e de uma nação. Postulou:

$\mathrm{O}$ congresso não deverá fazer qualquer lei a respeito do estabelecimento de religião, ou proibir o seu livre exercício; ou restringir a liberdade de expressão, ou da imprensa; ou o direito das pessoas de se reunirem pacificamente, e de fazerem pedidos ao governo para que sejam feitas reparações de queixas. ${ }^{18}$

A Déclaration dês Droits de l'Homme et Du Citoyen previu expressamente, nos artigos X e XI, as liberdades de pensamento, comunicação, opinião (ainda que religiosa), o falar, o escrever e o imprimir. ${ }^{19}$ Esse texto se destaca porque relaciona a liberdade de expressão à qualidade de direito humano.

Entretanto, embora as democracias estivessem se solidificando no continente europeu e no americano, os acontecimentos da Primeira e, principalmente, da Segunda Grande Guerra chocaram de tal forma a humanidade ocidental que, em 1948, a Assembleia Geral das Nações Unidas proclamou a Declaração Universal dos Direitos do Homem. Dentre inúmeros outros direitos, no artigo 19 reiterou-a como um direito humano:

\footnotetext{
${ }^{17}$ MILL, John, Stuart. Sobre a Liberdade. Tradução Ari Ricardo Tank Brito. São Paulo: Hedra, 2010, p. 64.

${ }^{18}$ ESTADOS UNIDOS DA AMÉRICA. Primeira Emenda, 15 de dezembro de 1791. Disponível em: < http:// www.direitoshumanos.usp.br/index.php/Documentos-anteriores-\%C3\%A0-cria\%C3\%A7\%C3\%A3o-da-Sociedade-das-Na\%C3\%A7\%C3\%B5es-at\%C3\%A9-1919/constituicao-dos-estados-unidos-da-america-1787.ht $\mathrm{ml}>$. Acesso em: 18 nov. 2015.

${ }^{19}$ Declaração dos direitos do homem e do cidadão. (1789). Disponível em: < http://www.direitoshumanos. usp.br/index.php/Documentos-anteriores-\%C3\%A0-cria\%C3\%A7\%C3\%A3o-da-Sociedade-das-Na\%C3\%A7\%C3\%B5es-at\%C3\%A9-1919/declaracao-de-direitos-do-homem-e-do-cidadao-1789.html>. Acesso em: 20 out. 2015
} 
Toda pessoa tem direito à liberdade de opinião e expressão; este direito inclui a liberdade de, sem interferência, ter opiniões e de procurar, receber e transmitir informações e idéias por quaisquer meios e independentemente de fronteiras. ${ }^{20}$

Vários são os fundamentos filosóficos que abonam a liberdade de expressão como um direito fundamental. Entre as principais razões, podem-se enumerar um de natureza constitutiva e outros de natureza instrumental. Num primeiro aspecto, a liberdade de expressão é um direito fundamental em razão de garantir a autossatisfação humana, apresentando-se como um fim em si mesma. A liberdade de expressão pode se apresentar ainda como um instrumento (um meio) para a realização de algo importante (um fim). Nesse sentido, esse direito ora se apresenta como um meio para a descoberta da verdade, ora como um meio para a efetivação do processo democrático ou até mesmo para a garantia do desenvolvimento da sociedade ou da estabilidade governamental ${ }^{21}$.

No Brasil, ela é considerada direito fundamental desde a Carta Imperial de 1824, restando presente em todas as Constituições subsequentes. Atualmente está regulamentada no inciso IV do artigo $5^{\circ}$ da Constituição brasileira, que protege a livre manifestação do pensamento, das ideias e das opiniões, e no inciso IX, que protege a livre comunicação para difundir e receber notícias, exercer o direito de informar, informar-se e ser informado.

\section{OS DIREITOS DA PERSONALIDADE COMO DIREITOS HUMANOS FUNDA- MENTAIS}

O conceito de direito da personalidade pode ser entendido sob duas vertentes: num sentido mais amplo, envolve direitos existenciais, direitos sobre o próprio corpo e direitos personalíssimos. Num sentido mais restrito, alguns autores entendem que protegeria apenas os atributos imateriais do homem, como a honra, a imagem, a moral, o nome, a intimidade, o segredo, a identidade pessoal, o recato, a voz, entre outros.

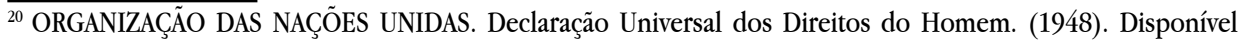
em: <http://www.direitoshumanos.usp.br/index.php/Declara\%C3\%A7\%C3\%A3o-Universal-dos-Direitos-Hum anos/declaracao-universal-dos-direitos-humanos.html> . Acesso em: 20 out. 2015.

${ }^{21}$ CHEQUER, Cláudio. Liberdade de expressão como direito fundamental preferencial "prima facie". Disponível em:<http:www.cartaforense.com.br/conteudo/artigos/liberdade-de-expressao-como-direito-fundamental -preferencial-prima-facie/5776>. Acesso em: 19 out. 2015.
} 
De modo geral, para Gustavo Tepedino ${ }^{22}$, poder-se-iam conceituar os direitos da personalidade como as "emanações da própria dignidade humana, funcionando como atributos inerentes e indispensáveis ao ser humano”. Já para Carlo Alberto Bittar, são direitos que concernem à dignidade da pessoa humana ${ }^{23}$.

Na lição de Francisco Amaral $^{24}$, depois dos horrores da Segunda Grande Guerra, do desenvolvimento da tecnologia, principalmente da biotecnologia e da massificação, a perspectiva de proteção mudou e o Estado liberal cedeu espaço a um Estado social intervencionista que concedeu maior proteção à dignidade do mais fraco na esfera privada diante da ganância desenfreada do poder dos mais fortes.

O valor 'dignidade humana' foi inserido nas Constituições do século $\mathrm{XX}$, podendo-se extrair a cláusula geral de promoção da pessoa, com o efetivo reconhecimento da tutela geral da personalidade. Foi nesse momento histórico que os direitos da personalidade se consolidaram na esfera privada, mantendo-se essa terminologia cunhada por Otto Gierke; enquanto na esfera pública, tais direitos continuaram conhecidos por direitos humanos ou fundamentais.

Gustavo Tepedino ${ }^{25}$ afirma que a tradicional classificação desses direitos deve-se afastar do típico direito subjetivo pessoal, ainda que direito subjetivo seja. Isso porque o intérprete precisa pretender não somente a proteção da dignidade humana mas a própria promoção da pessoa (por meio da cláusula geral de tutela da personalidade). Para o autor, a proteção não deve ser prioritariamente de caráter ressarcitório, como tende a prática dominante, mas da concreta satisfação da dignidade.

Os estudos de Carlos Alberto Bittar demonstram a natureza público/privada, até os dias de hoje, desses direitos:

De um lado, os 'direitos do homem' ou 'direitos fundamentais' da pessoa natural, como objeto de relações de direito público, para efeito de proteção do indivíduo contra o Estado. Incluem-se, nessa categoria, normalmente, os direitos: à vida; à integridade física; às partes do corpo; à liberdade; o direito de ação. De outro lado, consideram-se 'direitos da personalidade' os mesmos direitos, mas sob o ângulo das relações entre particulares, ou seja, da proteção contra outros homens. ${ }^{26}$

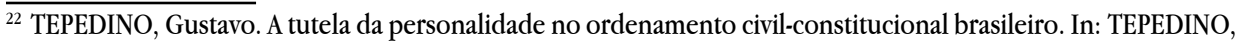
Gustavo. Temas de direito civil. 3. ed. Rio de Janeiro: Renovar, 1999, p. 30.

${ }^{23}$ BITTAR, Carlos Alberto. Os direitos da personalidade. 7. ed. Rio de Janeiro: Forense Universitária, 2008.

${ }^{24}$ AMARAL, Francisco. Direito civil: Introdução. 7. ed. Rio de Janeiro: Renovar, 2008,p. 257.

${ }^{25}$ TEPEDINO, Gustavo. A tutela da personalidade no ordenamento civil-constitucional brasileiro. In: TEPEDINO, Gustavo. Temas de direito civil. 3. ed. Rio de Janeiro: Renovar, 1999, p. 24.

${ }^{26}$ BITTAR, Carlos Alberto. Os direitos da personalidade. 7. ed. Rio de Janeiro: Forense Universitária. 2008, p. 26. 
Embora os direitos da personalidade (lato senso) estejam alocados em diversos dispositivos da Constituição, se eles forem compreendidos conceitualmente de modo restritivo, é possível concentrar-se uma análise no inciso X do artigo $5^{\circ}$ : "São invioláveis a intimidade, a vida privada, a honra e a imagem das pessoas, assegurado o direito a indenização pelo dano material ou moral decorrente de sua violação".

A proteção à imagem refere-se ao direito de decidir se e como ela será utilizada ou exposta. $\mathrm{O}$ direito à honra refere-se ao conceito de que o sujeito desfruta na sociedade (honra objetiva) bem como ao parâmetro de dignidade que o indivíduo elabora sobre si mesmo (honra subjetiva). A intimidade é o espaço que circunda o indivíduo, protegendo-o da curiosidade e indiscrição de terceiros.

\section{DIREITOS DA PERSONALIDADE E LIBERDADE DE EXPRESSÃO. O JULGA- MENTO NO STF SOBRE A CONSTITUCIONALIDADE DAS BIOGRAFIAS NÃO AU- TORIZADAS (ADI 4815/DF)}

O julgamento da ADI 4815, proposta pela Associação Nacional dos Editores de Livros, teve por objeto o pedido de inconstitucionalidade parcial sem redução de texto dos artigos 20 e 21 do Código Civil ${ }^{27}$ para que, mediante interpretação conforme a Constituição, fosse afastada a necessidade do prévio consentimento da pessoa biografada e, a fortiori, das pessoas retratadas como coadjuvantes (ou de seus familiares, em caso de pessoas falecidas) para a publicação ou veiculação de obras biográficas, literárias ou audiovisuais.

A análise central da discussão da ação refere-se ao conteúdo e à extensão do exercício do direito constitucional à expressão livre do pensamento da atividade intelectual, artística e de comunicação dos biógrafos, editores e entidades veiculadoras de obras biográficas ${ }^{28}$.

Embora os dispositivos impugnados sejam de direito privado, a colisão foi estabelecida entre normas de estatura constitucional vez que os direitos da personalidade à intimidade e à privacidade estão insertos na Constituição brasileira.

\footnotetext{
${ }^{27}$ Art. 20. Salvo se autorizadas, ou se necessárias à administração da justiça ou à manutenção da ordem pública, a divulgação de escritos, a transmissão da palavra, ou a publicação, a exposição ou a utilização da imagem de uma pessoa poderão ser proibidas, a seu requerimento e sem prejuízo da indenização que couber, se lhe atingirem a honra, a boa fama ou a respeitabilidade, ou se se destinarem a fins comerciais. Parágrafo único. Em se tratando de morto ou de ausente, são partes legítimas para requerer essa proteção o cônjuge, os ascendentes ou os descendentes. Art. 21. A vida privada da pessoa natural é inviolável, e o juiz, a requerimento do interessado, adotará as providências necessárias para impedir ou fazer cessar ato contrário a esta norma.

${ }^{28}$ LÚCIA, Cármem. Voto de relatoria na ADI 4815. Disponível em: <www..stf.jus.br/arquivo/cms/notíciasNoiciaStf/anexo ADI4815relatora.pdf>. Acesso em: 15 jul. 2015.
} 
Luís Barroso ${ }^{29}$ explica que a contemporânea interpretação constitucional é distinta da tradicional hermenêutica infraconstitucional. E que, ocorrendo hipótese de colisão entre direitos fundamentais, a melhor técnica a ser utilizada é ponderação, na qual o intérprete aferirá o peso de cada direito com vistas às circunstâncias, praticando concessões recíprocas. Sua aplicação, portanto, não será no esquema 'tudo ou nada', mas graduada à vista das circunstâncias representadas por outras normas ou por situações de fato. ${ }^{30}$

Para Ronald Dworkin, "quando os juristas dizem que os direitos podem ser limitados para proteger outros direitos ou para impedir uma catástrofe, eles têm em mente casos nos quais a causa e efeito são relativamente claros". ${ }^{31}$

Ainda que essa graduação retire completamente a eficácia de um dos direitos fundamentais, isso não invalida o raciocínio, como explica Robert Alexy ${ }^{32}$ :

O conteúdo essencial é aquilo a que se chega depois de uma ponderação. As restrições que dizem respeito ao princípio da proporcionalidade não lesionam a garantia do conteúdo essencial, ainda quando no caso particular não deixem nada do direito fundamental. A garantia do conteúdo essencial se reduz ao princípio da proporcionalidade.

A relatora da ação, ministra Carmén Lúcia, fundamentou sua decisão essencialmente na necessidade do respeito e fortalecimento do regime democrático brasileiro.

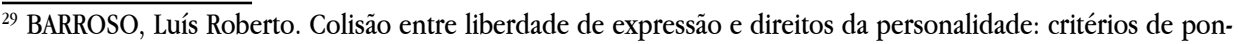
deração. Interpretação constitucionalmente adequada do código civil e da lei de imprensa. Disponível em: <www.migalhas.com.br/arquivo_artigo/art_03-10-01.htm>. Acesso em: 15 nov. 2015.

${ }^{30}$ Imagine-se uma hipótese em que mais de uma norma possa incidir sobre o mesmo conjunto de fatos, várias premissas maiores, portanto para apenas uma premissa menor, como no caso clássico da oposição entre liberdade de imprensa e de expressão, de um lado, e os direitos à honra, à intimidade e vida privada, de outro. Como se constata singelamente, as normas envolvidas tutelam valores distintos e apontam soluçóes diversas e contraditórias para a questão. Na sua lógica unidirecional (premissa maior- premissa menor), a solução subsuntiva para esse problema somente poderia trabalhar com uma das normas, o que importaria na escolha de uma única premissa maior, descartando-se as demais. Tal formula, todavia, não seria constitucionalmente adequada: por força do princípio instrumental da unidade da Constituição, o intérprete não pode simplesmente optar por uma norma e desprezar outra em tese também aplicável, como se houvesse hierarquia entre elas. A clareza é muito importante para que se possa conhecer a sutil diferença entre os objetos da ponderação que são dignos de sopesamento. E de alguma forma, cada um desses elementos deverá ser considerado na medida de sua importância e pertinência para o caso concreto, de modo que na solução final, tal qual em um quadro bem pintado, as diferentes cores possam ser percebidas, ainda que uma ou algumas delas venham a se destacar sobre as demais. Esse é, de maneira geral, o objeto daquilo que se convencionou denominar técnica da ponderação. BARROSO, Luís Roberto. Interpretação e Aplicação da Constituição. 6. ed. São Paulo: Saraiva, 2004. p.357.

${ }^{31}$ DWORKIN, Ronald. Levando os direitos a sério. 2. ed. São Paulo: Martins Fontes, 2007, p. 197.

${ }^{32}$ ALEXY, Robert. Teoria dos direitos fundamentais. Tradução Virgílio Afonso da Silva. 2. ed. São Paulo: Malheiros, 2011. p. 274. 
No julgamento da ação foram reacendidas as lições inaugurais oitocentistas nas quais Montesquieu e Rousseau configuraram as bases do Estado Democrático de Direito, delineando os papéis das liberdades fundamentais para a estabilidade futura dos governos e das garantias individuais.

A recente história do Brasil é marcada pela ditadura militar bem como pela implantação da censura com o consequente cerceamento das formas de expressão. A partir do Ato Institucional $n^{0} 5$, de 1968, e de sucessivas normas antidemocráticas, inúmeras garantias e liberdades individuas foram suspensas, permanecendo assim até meados dos anos 1980, período coincidente com a redemocratização do país. O que se pretendeu após foi o fortalecimento da circulação de fatos e ideias para que cada cidadão pudesse participar da construção do novo debate público com opinião livre, sem o que não há que se falar em democracia participativa.

No julgamento, o ministro Dias Toffoli acentuou que a Corte estava, naquela ocasião, afastando a ideia de censura uma vez que no Estado Democrático de Direito essa é inaceitável ${ }^{33}$. Nessa mesma linha de pensamento, a ministra Rosa Weber manifestou o entendimento de que controlar as biografias implica tentar controlar ou apagar a história e que a autorização prévia constitui uma forma de censura, incompatível com o Estado Democrático de Direito. ${ }^{34}$

Jónatas Machado $^{35}$ concebe que o princípio democrático e o próprio desenvolvimento dos direitos fundamentais estão associados à liberdade e à multiplicidade de ideias. Ronald Dworkin ${ }^{36}$ assevera que a democracia não se expressa apenas por meio do sufrágio, mas sim por meio de três dimensões, sendo a terceira a do discurso democrático, ou seja, para ele, se o discurso público estiver restringido pela censura, o autogoverno coletivo fracassa ${ }^{37}$.

Sendo a liberdade de expressão considerada um direito fundamental, quando estiver relacionada com conteúdo de direito público, será considerada preferencial e a balança da ponderação deverá ser pendida a seu favor. "A liberdade de expressão é garantia preferencial em razão da estreita relação com outros

\footnotetext{
33 TOFFOLI, José Antonio Dias. Voto proferido em plenário no julgamento da ADI 4815 de 10/06/2015. Disponível em: <https://www.youtube.com/watch?v=TMaO9zcLwFM > . Acesso em: 28 jun. 2015.

${ }^{34}$ WEBER, Rosa Maria. Voto proferido em plenário no julgamento da ADI 4815 de 10/06/2015. Disponível em: $<$ https://www.youtube.com/watch?v=TMaO9zcLwFM > . Acesso em: 28 jun. 2015.

${ }^{35}$ MACHADO, Jónatas Eduardo Mendes. Liberdade de Expressão: dimensões constitucionais da esfera pública no sistema social. Coimbra: Coimbra, 2002. p. 53.

${ }^{36}$ DWORKIN, Ronald. La Virtud Soberana: La Teoría y la Práctica de la Igualdad. Barcelona: Paidós, 2003.

${ }^{37}$ A primeira dimensão implica em que diversos funcionários governem, representando a soberania popular, e a segunda é a da igualdade, devendo o voto de todos ter o mesmo peso.
} 
princípios e valores constitucionais fundantes, como a democracia, a dignidade da pessoa humana e a igualdade" 38 .

Para Luis Barroso, por pressupostos filosóficos e teóricos e por questões fáticas específicas brasileiras, pode-se afirmar que a liberdade de expressão deve ser tratada de modo preferencial por três motivos. Em primeiro ponto, ela é tão acidentada e tão sofrida que precisa ser afirmada e reafirmada em ato contínuo e eventualmente com certo exagero. Em segundo, não é somente um pressuposto democrático como é também um pressuposto para o exercício dos outros direitos fundamentais e para a plenitude dos outros direitos, sejam eles privados ou públicos. Em terceiro, ela é essencial para o conhecimento da história e para a conservação da memória nacional ${ }^{39}$.

Para Sérgio Moro, a Suprema Corte americana elevou a liberdade de expressão e do pensamento à posição preferencial com base em sua íntima ligação com a democracia que, para ser sólida, demanda amplos direitos de participação ${ }^{40}$. Ingo Sarlet ${ }^{41}$ leciona:

Dada a sua relevância para a democracia e o pluralismo político, a liberdade de expressão - pelo menos de acordo com significativa doutrina - assume uma espécie de posição preferencial (preferred position), quando da resolução de conflitos com outros princípios constitucionais e direitos fundamentais, muito embora se afirme que no Brasil a teoria da posição preferencial - em que pese consagrada pelo STF quando do julgamento da ADPF 130 - tem sido, em geral, aplicada de forma tímida. De qualquer modo, não se trata de atribuir à liberdade de expressão (em qualquer uma de suas manifestações particulares) a condição de direito absolutamente imune a qualquer limite e restrição, nem de estabelecer uma espécie de hierarquia prévia entre as normas constitucionais. Assim, quando se fala de uma posição preferencial - pelo menos no sentido em que aqui se admite tal condição -, tem-se a finalidade de reconhecer à liberdade de expressão uma posição de vantagem no caso de conflitos com outros bens fundamentais no que diz com a hierarquização das posições conflitantes no caso concreto, de tal sorte que também nessa esfera - da solução para eventual conflito entre a liberdade de expressão e outros bens fundamentais individuais e coletivos - não há como

${ }_{38}$ MELLO, Marco Aurélio Mendes de Farias. Voto em plenário na ADI 4815. Disponível em < http://www.youtube.com/watch?v=TMaO9zcLwFM > . Acesso em: 10 set. 2015.

${ }^{39}$ BARROSO, Luis Roberto. Voto em plenário na ADI 4815. Disponível em < http://www.youtube.com/watch?$\mathrm{v}=\mathrm{i}-\mathrm{M} 3 \mathrm{BH} 44 \mathrm{SN} 4>$. Acesso em: 15 set. 2015.

${ }^{40}$ MORO, Sérgio Fernando. Jurisdição constitucional como democracia. São Paulo: Revista dos Tribunais, 2004.

${ }^{41}$ SARLET, Ingo Wolfgang. Direitos Fundamentais em espécie. In: SARLET, Ingo Wolfgang, MARINONI, Luiz Guilherme; MITIDIERO, Daniel. Curso de Direito Constitucional. 3. ed. São Paulo: Revista dos Tribunais, 2014. p.460-461. 
deixar de considerar as exigências da proporcionalidade e de outros critérios aplicáveis a tais situações.

Em lato senso, podem-se sustentar duas teorias em torno dos limites aos direitos fundamentais: uma interna e outra externa. Para a primeira, jamais se verifica qualquer tipo de conflito ou colisão entre direitos, ocorrendo somente uma delimitação no campo de incidência de cada um. A teoria externa, ao contrário, assente a colisão, admitindo o processo restritivo por meio da ponderação de bens (identificando o núcleo do direito fundamental em análise e o delimitando de acordo com outros direitos de mesma envergadura). Pela análise dos votos proferidos em plenário, essa última foi a corrente amplamente utilizada no julgamento exame ${ }^{42}$.

Porém, apesar de gozarem de patamar preferencial, Gilmar Mendes ${ }^{43}$ adverte que a liberdade de expressão e a de informação não são absolutas: "Portanto, tal como no direito alemão, afigura-se a legítima outorga de tutela judicial contra a violação dos direitos de personalidade, especialmente dos direitos à honra e à imagem, ameaçados pelo exercício abusivo da liberdade de expressão e de informação". Continua o autor que são possíveis diversas formas de reparação em caso de lesão aos direitos da personalidade como, por exemplo, a publicação de ressalva ou nova edição com correção $0^{44}$.

Como demonstrado, a Constituição brasileira, tal como a Constituição alemã, conferiu significado especial aos direitos da personalidade, consagrando o princípio da dignidade humana como postulado essencial da ordem constitucional, estabelecendo a inviolabilidade do direito à honra e à privacidade e fixando que a liberdade de expressão e de informação haveria de observar o disposto na Constituição, especialmente o estabelecido no art. $5^{\circ}, \mathrm{X} .{ }^{45}$

Constitui uma restrição importante à liberdade de expressão e de comunicação o discurso do ódio, seguindo caminho paralelo aos Estados Unidos

\footnotetext{
$\overline{42}$ Até esta data, 20/11/2015, somente os votos escritos da ministra relatora e do ministro Luis Roberto Barroso estavam disponíveis no site do STF.

43 MENDES, Gilmar Ferreira. Colisão de direitos fundamentais: liberdade de expressão e de comunicação e de direito à honra e à imagem. Revista de Informação Legislativa, v..31, nº122, p.301, maio/jun.1994. Disponível em: <www.http://www2.senado.leg.br/bdsf/bitstream/handle/id/176193/000487451.pdf?sequence=3>. Acesso em: 08 nov. 2015.

${ }^{44}$ MENDES, Gilmar Ferreira. Voto proferido em plenário no julgamento da ADI 4815 de 10/06/2015. Disponível em https://www.youtube.com/watch?v=TMaO9zcLwFM. Acesso em 28/06/2015.

${ }^{45}$ MENDES, Gilmar Ferreira. Colisão de direitos fundamentais: liberdade de expressão e de comunicação e de direito à honra e à imagem. Revista de Informação Legislativa. a.31, nº122, p.300, mai./jun.1994. Disponível em: <www.http://www2.senado.leg.br/bdsf/bitstream/handle/id/176193/000487451.pdf?sequence=3>. Acesso em: 08 nov. 2015.
} 
quanto ao material obsceno. Uma resposta emblemática à manifestação de ódio foi decisão proferida no HC 82.424/RS. O Supremo Tribunal Federal manteve a condenação do editor Siegfried Ellwanger, imposta pelo Tribunal de Justiça do Rio Grande do Sul por crime de racismo. A condenação ocorreu por ele editar e distribuir obras de conteúdo antissemita. O tribunal entendeu que a liberdade de expressão não legitima a disseminação de ódio contra as pessoas e a ofensa à dignidade da pessoa humana.

Por fim, pode-se afirmar que o julgamento da ADI 4815 foi especial e paradigmático por alguns motivos que seguem. Em primeiro lugar, porque foi por unanimidade (o que não é comum nas últimas composições de ministros no Tribunal). Em segundo, porque todos os votos tiveram como lastro, em suma, o mesmo fundamento: a preservação e o robustecimento do Estado Democrático de Direito, por meio da permissão, sem censura ou licença, da livre produção, circulação e divulgação de conteúdo privado ou público de pensamento, pessoal ou coletivo, privado ou público. E, finalmente, em terceiro lugar, porque a discussão não se restringiu às academias jurídicas, gerando intenso debate social e midiático com acompanhamento participativo pela população por meio de 'enquetes' e outras formas de interação com o público.

\section{CONSIDERAÇÕES FINAIS}

A ação foi julgada procedente para dar interpretação conforme a Constituição sem redução de texto aos artigos 20 e 21 da lei civil (que continuam hígidos) para, em consonância com os direitos fundamentais à liberdade de pensamento e de expressão, de criação artística e de produção científica, declarar inexigível o consentimento de pessoa biografada relativamente a obras biográficas literárias ou audiovisuais; sendo por igual desnecessário autorização de pessoas retratadas como coadjuvantes (ou de seus familiares, em caso de pessoas falecidas).

Os direitos da personalidade, não obstante previstos na ordenação privatista, são tutelados no ordenamento constitucional, estabelecendo, assim, uma colisão entre esses direitos e a liberdade de expressão. A gênese do liberalismo burguês propugnou pelas liberdades individuais, acentuadamente a de pensamento e a de expressão. Avançaram em conjunto e se tornaram correspondentes e indissociáveis porque referentes à soberania popular. 
Como em outras decisões pretéritas, o Supremo Tribunal Federal tem afirmado a tese de que, em colisão com os demais direitos fundamentais, a liberdade de expressão tem preferência. Isso porque esta viabiliza os livres debates públicos, instruindo os cidadãos no exercício de sua cidadania e promovendo, em último grau, a República Federativa do Brasil como Estado democrático de Direito (caput do art. $1^{\circ}$ da Constituição brasileira).

De John Locke e Stuart Mill ao Supremo Tribunal Federal, o sujeito de direitos, a liberdade de expressão e o Estado democrático de Direito triunfaram. O jusnaturalismo de Rousseau, que inspirou a Revolução Francesa e a Declaração dos Direitos do Homem e do Cidadão, está impresso em todos os direitos fundamentais da Constituição brasileira. A técnica da ponderação, legado alemão para solucionar uma pugna dessa grandeza constitucional, cumpriu seu papel nesse julgamento. Ao menos é o que a decisão, por unanimidade, indica.

\section{REFERÊNCIAS}

ALEXY, Robert. Teoria dos direitos fundamentais. Tradução Virgílio Afonso da Silva. 2. ed. São Paulo: Malheiros, 2011.

AMARAL, Francisco. Direito civil: introdução. 7. ed. Rio de Janeiro: Renovar, 2008.

BARROSO, Luís Roberto. Interpretação e aplicação da constituição. 6. ed. São Paulo: Saraiva, 2004.

BARROSO, Luís Roberto. Voto em plenário na ADI 4815. Disponível em < http:// www. youtube.com/watch?v=i-M3BH44SN4>. Acesso em: 15 set. 2015.

BARROSO, Luís Roberto. Colisão entre Liberdade de Expressão e Direitos da Personalidade. Critérios de Ponderação. Interpretação Constitucionalmente adequada do Código Civil e da Lei de Imprensa. Disponível em: <www.migalhas. com.br/arquivo_artigo/art_03-10-01.htm > . Acesso em: 15 nov. 2015.

BITTAR, Carlos Alberto. Os direitos da personalidade. 7. ed. Rio de Janeiro: Forense Universitária, 2008. 
BRASIL. Código Civil. São Paulo: Saraiva, 2015.

BRASIL. Constituição Federal do Brasil. São Paulo: Saraiva, 2015.

BRASIL. Supremo Tribunal Federal. Arguição de Descumprimento de Preceito fundamental no 130, de 30 de abril de 2009. Disponível em: < http://redir.stf.jus. $\mathrm{br} /$ paginadorpub/paginador.jsp?docTP $=\mathrm{AC} \& \mathrm{docID}=605411>$. Acesso em: $10 \mathrm{jul}$. 2015.

CANOTILHO, J. J. Gomes. Direito Constitucional e teoria da Constituição. 6. ed., Coimbra: Almedina, 1993.

CARVALHO, Salo de; Flores, Joaquím Herrera; RUBIO, David Sánchez. Direitos Humanos e Globalização: fundamentos e possibilidades desde a teoria crítica. Brasília: Lumem Juris, 2004.

CHEQUER, Cláudio. Liberdade de expressão como direito fundamental preferencial "prima facie". Disponível em:<http:www.cartaforense.com.br/ conteudo/artigos/liberdade-de-expressao-como-direito-fundamental-preferencialprima-facie/5776>. Acesso em: 19 out. 2015.

COMPARATO, Fábio Konder. A afirmação histórica dos direitos humanos. 6. ed. São Paulo: 2008.

DECLARAÇÃO DOS DIREITOS DO HOMEM E DO CIDADÃO. (1789). Biblioteca Virtual de Direitos Humanos. Universidade de São Paulo. Disponível em: < http://www. direitoshumanos.usp.br/index.php/Documentos-anteriores-\%C3\%A0cria\%C3\% A7\%C3\%A3o-da-Sociedade-das-Na\%C3\%A7\%C3\%B5es-at\%C3\%A9-1919/declaracaode-direitos-do-homem-e-do-cidadao-1789.html > . Acesso em: 10 jul. 2015.

DESCARTES, René. Discurso do método. Tradução Maria Ermantina Galvão. São Paulo: Martins Fontes, 2001.

DWORKIN, Ronald. Levando os direitos a sério. 2. ed. São Paulo: Martins Fontes, 2007.

DWORKIN, Ronald. La Virtud Soberana: La Teoría y la Práctica de la Igualdad. Barcelona: Paidós, 2003. 
ESTADOS UNIDOS DA AMÉRICA. Primeira Emenda, 15 de dezembro de

1791. Disponível em: <http://www.direitoshumanos.usp.br/index.php/ Documentos-anteriores-\%C3\%A0-cria\%C3\%A7\%C3\%A3o-da-Sociedade-dasNa\%C3\%A7\%C3\%B5es-at\%C3\%A9-1919/constituicao-dos-estados-unidos-daamerica-1787.ht ml>. Acesso em: 18 nov. 2015.

ESTADOS UNIDOS DA AMÉRICA. Declaração dos direitos da Virgínia. (1776). Disponível em: <http://www.direitoshumanos.usp.br/index.php/ Documentos-anteriores-\%C3\%A0cria\%C3\% A7\%C3\%A3o-da-Sociedade-dasNa\%C3\%A7\%C3\%B5es-at\%C3\%A9-1919/declaracao-de-direitos-do-bom-povo-devirginia-1776.html>. Acesso em: 10 jul. 2015.

HENKIN, Louis. The rights of man today. New York: Columbia University Press, 1988.

HOBBES, Thomas. Leviatã. São Paulo: Martin Claret, 2002.

KANT, Immanuel. Crítica à Razão Pura. Tradução Manuela Pinto dos Santos; Alexandre Fradique Morujão. 5. ed. Lisboa: Edição da Fundação Calouste Gulbenkian, 2001.

KANT, Immanuel. Crítica à Razão Prática. Tradução Afonso Bertagnoli. São Paulo: Edições e Publicações Brasil, 2004. Disponível em: < http://www.ebooksbrasil.org/ eLibris/razaopratica.html> . Acesso em: 29 set. 2015.

LOCKE, John. Carta sobre a tolerância. Tradução Ari Ricardo Tank Brito. São Paulo: Hedra, 2007.

LOCKE, John. Segundo Tratado sobre o governo civil. Tradução Magda Lopes; Marisa Lobo da Costa. Petrópolis: Vozes, 1987.

LOEWENSTEIN, Karl. Teoría de la Constitución. 2 ed. Barcelona: Ariel, 1970.

LÚCIA, Carmén. Voto de relatoria na ADI 4815. Disponível em: < http://www.stf. jus.br/arquivo/cms/noticiaNoticiaStf/anexo/ ADI4815relatora.pdf $>$. Acesso em: 15 jul. 2015. 
MACHADO, Jónatas Eduardo Mendes. Liberdade de Expressão: dimensões constitucionais da esfera pública no sistema social. Coimbra: Coimbra Editora, 2002.

MBAYA, Etienne-Richard. Gênese, evolução e universalidade dos direitos humanos frente à diversidade de culturas. p. 20-21. Disponível em: <http:// www.revistas.usp.br/eav/article/viewFile/8993/10545> . Acesso em 20 out. 2015.

MENDES, Gilmar Ferreira. Colisão de direitos fundamentais: liberdade de expressão e de comunicação e de direito à honra e à imagem. Revista de Informação Legislativa, v. 31, n.122, p. 301, maio/jun.1994. Disponível em: < http://www2. senado. $\quad$ leg.br/bdsf/bitstream/handle/id/176193/000487451.pdf?sequence $=3>$. Acesso em: 08 nov. 2015.

MENDES, Gilmar Ferreira. Voto proferido em plenário no julgamento da ADI 4815 de 10/06/2015. Disponível em: <https://www.youtube.com/ watch?v=TMaO9zcLwFM $>$. Acesso em: 28 jun. 2015.

MELLO, Marco Aurélio Mendes de Farias. Voto em plenário na ADI 4815. Disponível em < http://www. youtube.com/watch?v=TMaO9zcLwFM $>$. Acesso em: 10 set. 2015 .

MILL, John Stuart. Sobre a Liberdade. Tradução Ari Ricardo Tank Brito. São Paulo: Hedra, 2010.

MORAES, Alexandre de. Direitos humanos fundamentais: teoria geral: comentários aos artigos $1^{\circ}$ ao $5^{\circ}$ da constituição. 2. ed. São Paulo: Atlas, 1997.

MORO, Sérgio Fernando. Jurisdição constitucional como democracia.São Paulo: Revista dos Tribunais, 2004.

OLIVEIRA JÚNIOR, Claudomiro Batista de. Afirmação histórica e jurídica da liberdade de expressão. In: CONGRESSO NACIONAL DO CONPEDI, 17., 2008, Brasília. Anais... Florianópolis: CONPEDI, 2008. p. 5777-5795. Disponível em: <http:// www.conpedi.org.br/manaus/arquivos/anais/brasilia/05_395.pdf $>$. Acesso em: 15 set. 2015.

ORGANIZAÇÃO DAS NAÇÕES UNIDAS. Declaração Universal dos Direitos do Homem. (1948). Disponível em < http://www.direitoshumanos.usp.br/index. php/ 
Declara\%C3\%A7\%C3\%A3o-Universal-dos-Direitos-Humanos/declaracao-universaldos-direitos-humanos.html> . Acesso em: 20 jul. 2015.

PIOVESAN, Flávia. Direitos humanos e o direito constitucional internacional. 14. ed. São Paulo: Saraiva, 2013.

SARLET, Ingo Wolfgang. Direitos fundamentais em espécie. In: SARLET, Ingo Wolfgang; MARINONI, Luiz Guilherme. MITIDIERO, Daniel. Curso de direito constitucional. 3. ed. São Paulo: Revista dos Tribunais, 2014.

TEPEDINO, Gustavo. A tutela da personalidade no ordenamento civil-constitucional brasileiro. In: TEPEDINO, Gustavo. Temas de direito civil. 3. ed. Rio de Janeiro: Renovar, 1999.

TOFFOLI, José Antonio Dias. Voto proferido em plenário no julgamento da ADI 4815 de 10/06/2015. Disponível em: < https://www.youtube.com/ watch? $=$ TMaO9zcLwFM $>$. Acesso em: 28 jun. 2015.

WEBER, Rosa Maria. Voto proferido em plenário no julgamento da ADI 4815 de 10/06/2015. Disponível em: <https://www.youtube.com/ watch?v=TMaO9zcLwFM > . Acesso em: 28 jun. 2015.

Recebido em: 31 de agosto de 2015 Aceito em: 07 de janeiro de 2016 
